\title{
Acute Calcific Prevertebral Tendinitis Nonvisible in Plain Radiograph
}

\author{
Jin Hwan Kim ${ }^{1}$, Si-Yung Lee ${ }^{1}$ and Ick Soo Choi ${ }^{2 *}$ \\ ${ }^{1}$ Department of Orthopedic Surgery, Inje University \& Ilsan Paik Hospital, Korea \\ ${ }^{2}$ Department of Otorhinolaryngology, Inje University \& Ilsan Paik Hospital, Korea
}

Submission: May 02, 2018; Published: May 09, 2018

*Corresponding author: Ick Soo Choi, Department of Otorhinolaryngology-Head and Neck Surgery, Ilsan Paik Hospital \& Inje University College of Medicine, Goyang, Republic of Korea, 170, Juhwa-ro, Ilsanseo-gu, Goyang-si, Gyeonggi-do, 10380, Rep. of Korea, Tel: +82-31-910-7250;

Fax: +82-31-910-7219; Email: leochoics@gmail.com

Abstract

Calcific tendinitis of the longus colli is an inflammatory disease caused by calcium hydroxyapatite crystal deposition in the longus colli tendon of the prevertebral space. The typical imaging characteristics of this entity are calcifications on the longus colli tendons at the C1-2 level and fluid collection in the retropharyngeal space in plain radiograph. Usually, calcific lesion can be detected by plain radiograph. We introduce 2 case of prevertebral calcific tendinitis nonvisible in plain radiograph, but the diagnosis was confirmed on computerized tomography.

Keywords: Tissue plasminogen activator; Hemorrhage; Stroke; Blepharoplasty; Ectropion Ischemic stroke; Complications; Treatment.

\section{Introduction}

Many population have neck pain at some time in their lives. According to the Global Burden of Disease 2016 Study, neck pain is the fourth leading cause of years lost to disability, ranking behind back pain, depression, and arthralgia [1]. And the lifetime prevalence for the rest of the adult population (18-84 years) ranged from $14.2 \%$ to $71 \%$ with a mean of $48.5 \%$ [2]. A variety of causes of neck pain have been described and include osteoarthritis, discogenic disorders, trauma, tumors, infection, myofascial pain syndrome, torticollis, and whiplash injury. Unfortunately, clearly defined diagnostic criteria have not been established for many of these entities [3]. Plain radiograph can be helpful in diagnosing neck pain.

Calcific tendinitis of the longus colli, also known as prevertebral tendinitis or retropharyngeal calcific tendinitis, is an uncommon benign condition caused by calcium hydroxyapatite deposition in the longus colli tendon and inflammation of the longus colli muscle. The clinical presentation is often nonspecific characterized by spontaneous acute or subacute neck pain and low-grade fever. Laboratory tests may demonstrate a mild leukocytosis and erythrocyte sedimentation rate (ESR) is slightly elevated. Differential diagnosis between retropharyngeal tendinitis and other diseases shows similar clinical features, such as atlantoaxial subluxation, retropharyngeal abscess, meningitis, infectious spondylitis. Retropharyngeal abscess is one of the most serious disease to differentiate with calcific tendinitis.

The typical radiographic findings of retropharyngeal calcific tendinitis are prevertebral soft tissue thickness and amorphous calcification anterior to C1-C2. However, It is very difficult to distinguish the early stage of retropharyngeal calcific tendinitis from other disease, if it is invisible in plain radiograph.

We report two patients who are acute calcific prevertebral tendinitis without any calcific mass at prevertebral area on plain radiograph $[4,5]$.

\section{Case 1}

A 41-year-old female patient presented with a 1-week history of a painful neck. She had no history of trauma, upper respiratory infection. The pain gradually worsened 3 days ago from admission. The day before admission to the hospital, the patient's pain was aggravated worse with decreased neck motion. After hospitalization, she complained of neck pain, stiffness of neck and dysphagia. But did not complain fever or heating sense. On physical examination, there was reduced active range of neck motion in all directions limited due to pain. There was no other radiating pain or neurologic deficit to the upper extremity. Mild tenderness was noted on the anterior and posterior neck area. But the oropharyngeal examination was normal, with no associated cervical lymphadenopathy. There was no abnormal findings such as fracture, subluxation or abnormal calcification finding on cervical spine radiograph (Figure 1). In C-spine lateral view, the diameter of C3 level prevertebral soft tissue thickness was $4.9 \mathrm{~mm}$ as a normal range (C3 upper limit normal range is $18 \mathrm{~mm}$ ) [6]. In CT and MRI, An amorphous calcification was detected, that was $8.0 \times 6.4 \times 3 \mathrm{~mm}$ anterior to $\mathrm{C} 1-\mathrm{C} 2$ and retropharyngeal space fluid collection 


\section{Journal of Head Neck \& Spine Surgery}

was also detected at the same period of time (Figure 2). Finally, acute calcific prevertebral tendinitis was our impression and she was started on nonsteroidal anti-inflammatory drugs per oral.
(NSAIDS).(Aceclofenac 1 tablet, Streptokinase 1 tablet, twice a day) After Two days on medication, visual analogue scale pain score decreased from 7 points to 2 points.

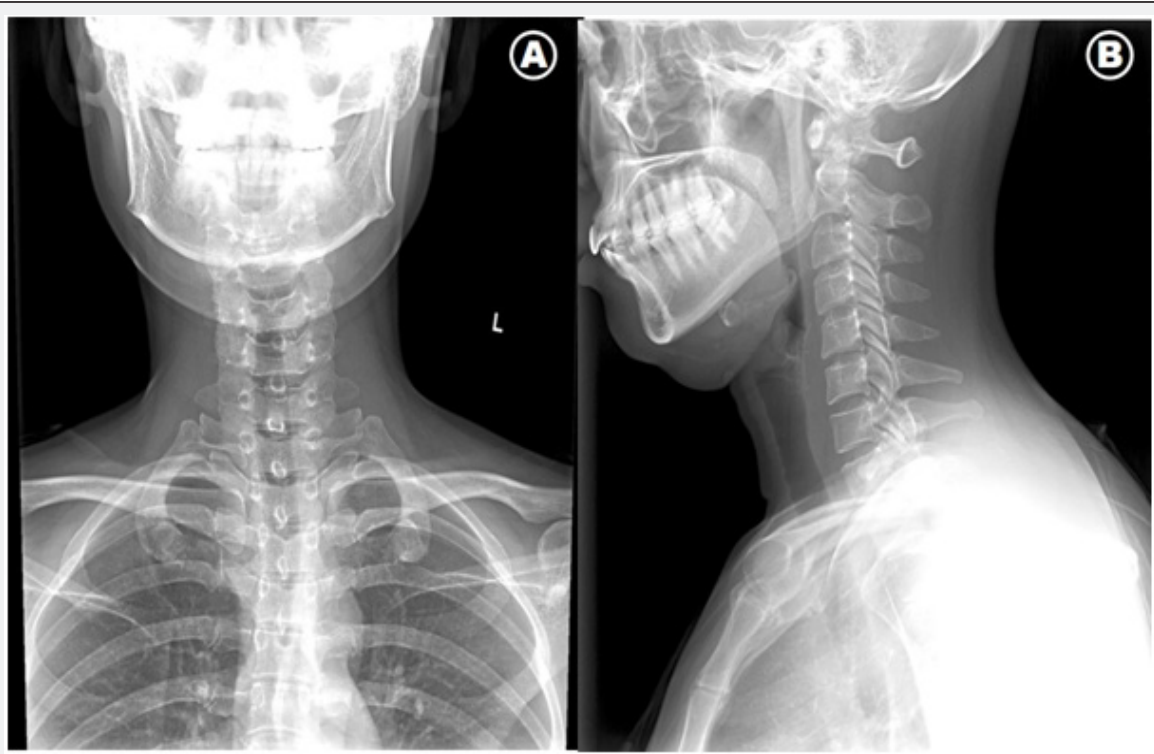

Figure 1: Case 1: Plain radiograph of the cervical spine AP and lateral view: A calcification or other abnormal findings was not found in prevertebral space.

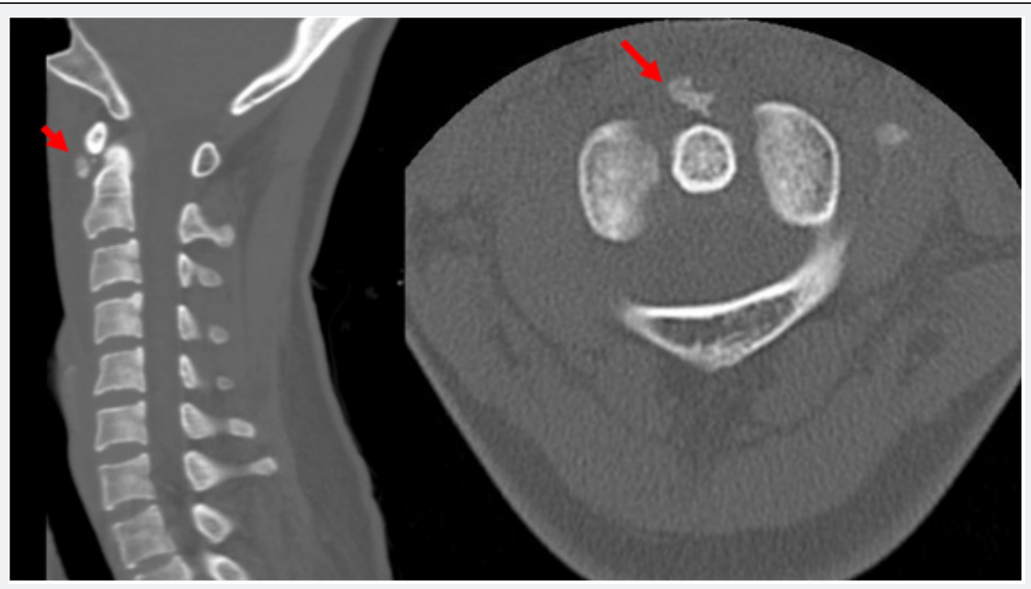

Figure 2: Case 1: CT scan shows the presence of amorphous calcific density within the prevertebral space on C1-2(arrow).

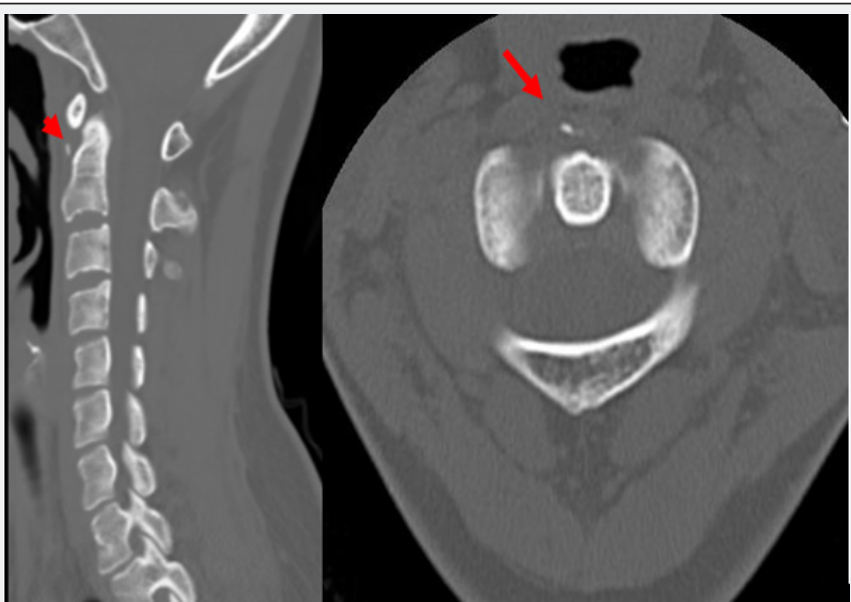

Figure 3: Case 1: Follow-up CT of patient 4 weeks later reveals significantly reduced size of the calcific density (arrow). 
The symptoms were improved with nearly full recovered range of motion of neck after 10 days on medication. Laboratory tests were slightly elevated C-reactive protein (CRP) and normal ESR. After 1 week later with treatment, ESR and CRP are decreased to the normal range. In follow-up CT approximately 1 month later, it was significantly resolved calcification, size of which was $3.2 \times .2 .1 \times 1.0 \mathrm{~mm}$ (Figure 3).

\section{Case 2}

A 43-year-old female patient presented with one day history of severe neck pain and aggravated by particular movements. There was no history of fever, recent illnesses or past events. On physical examination, we found a reduced active range of neck motion in flexion and extension; particularly on the extension due to pain. The rotation of the neck from side to side was a little possible. There is no fracture or subluxation or abnormal calcification finding on cervical spine radiograph. In C-spine lateral view, the diameter of C3 level prevertebral soft tissue thickness was $4.7 \mathrm{~mm}$ and C6 level was $12.7 \mathrm{~mm}$; it is within normal range (Figure 4) [6]. CT of the cervical spine confirmed that the calcific density mass was irregular shape and amorphous and size was $5.3 \times 6.3 \times 3.5 \mathrm{~mm}$ anterior to C4-5 (Figure $5)$. The diagnosis of acute calcific prevertebral tendinitis was made and the patient was started on a regimen of nonsteroidal anti-inflammatory drugs per oral. (NSAIDS). (Meloxicam 7.5mg, Eperisone 100mg, twice a day).

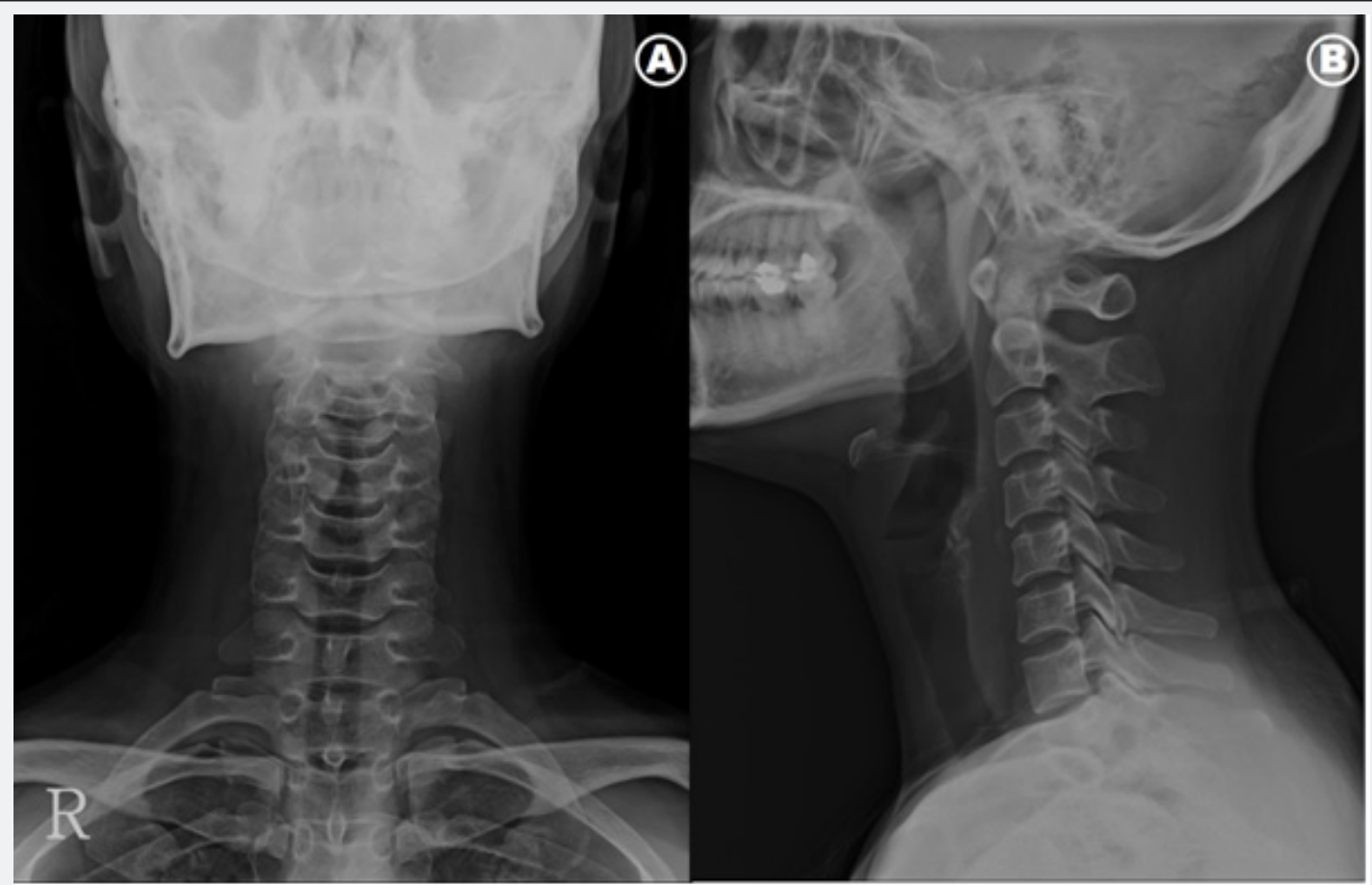

Figure 4:Case 2: Plain radiograph of the cervical spine AP and lateral view: A calcification or other abnormal findings was not found in prevertebral space.

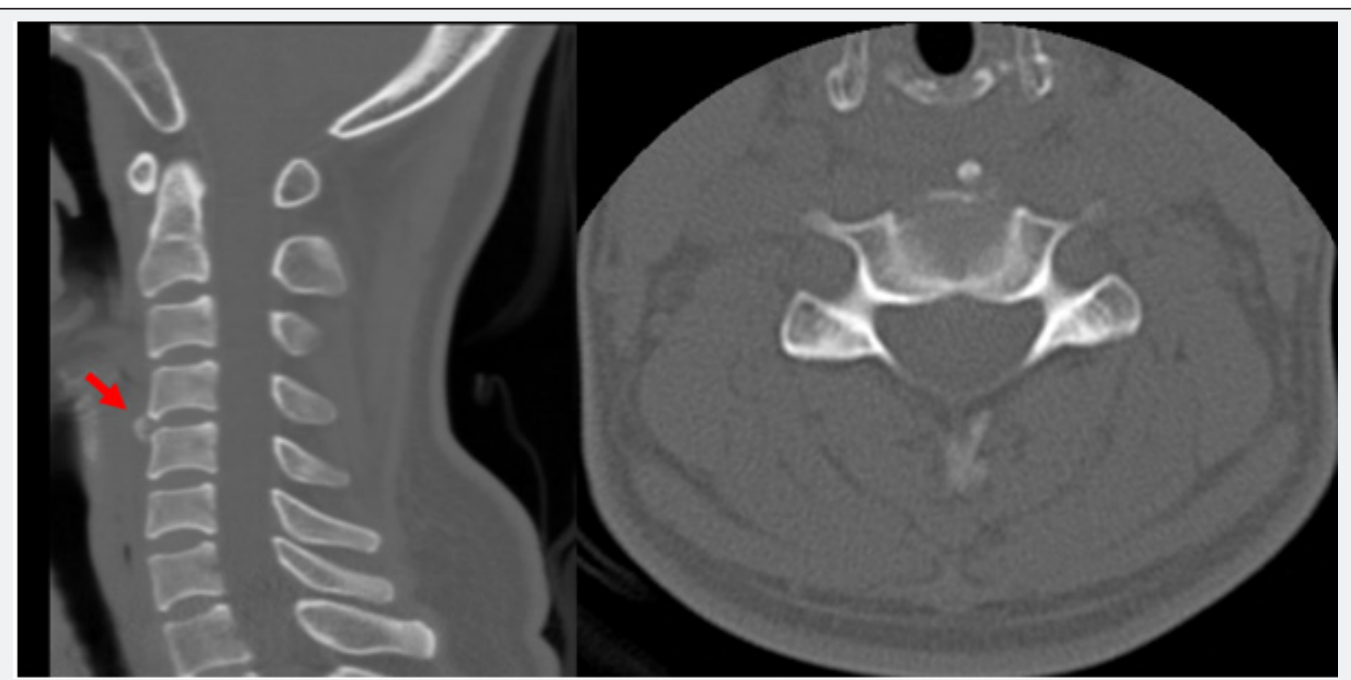

Figure 5: Case 2: CT scan shows the presence of amorphous calcific density within the prevertebral space on C4-5(arrow) 


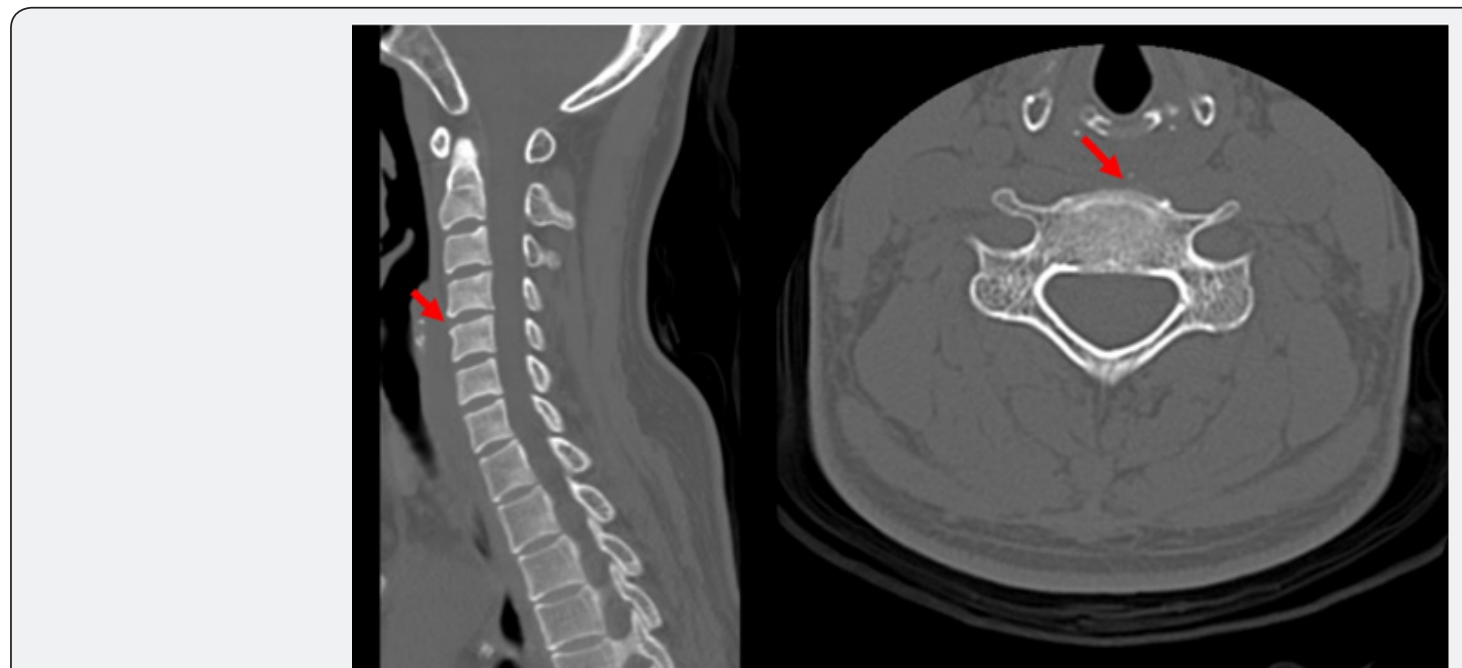

Figure 6: Case 2: Follow-up CT of patient 7 weeks later reveals complete resolution of the calcific density (arrow).

After 2 weeks, she had almost fully recovered after receiving conservative treatment that including anti-inflammatory drugs and rest. In 7 weeks later follow-up CT, the calcific lesion was almost completely resolved (Figure 6).

\section{Discussion}

There are many report concerning about acute calcific tendinitis is an inflammatory disease caused by calcium hydroxyapatite crystal deposition in the longus colli tendon of the prevertebral space. It is also known as retropharyngeal calcific tendinitis or prevertebral tendinitis.

Hartley first described retropharyngeal calcific tendinitis in 1964 and was shown by Ring and colleagues in 1994 to be due to hydroxyapatite deposition in the longus collimuscle $[7,8]$. The etiology of calcium hydroxyapatite crystal deposition is unclear, and there are some suggestions that repetitive trauma, recent injury, tissue necrosis, or ischemia may play a role.

It is believed that once the calcium crystals have deposited within the longus colli muscle, they invoke a painful foreign body-like inflammatory response [9].

Acute calcific retropharyngeal tendinitis affects adults with the greatest distribution between 30 and 60 years. The clinical pattern is nonspecific, including acute to subacute onset of neck pain, dysphagia and low-grade fever. Dysphagia is due to the close proximity between the retropharyngeal spaces [10]. The range of motion is extremely limited, usually secondary to severe pain, especially in flexion and extension. Oropharynx and hypopharynx exam performed by an otolaryngologist observed swelling and redness of mucosa. Since WBC or CRP can be slightly elevated, lab tests do not give significant value in differentiating calcific tendinitis from postpharyngeal infection or abscess [11]. Retropharyngeal abscess is initially based upon clinical symptoms and signs on physical examination. Torticollis, fever, and dysphagia represent a classic triad of symptoms. In addition, dysphagia, and limited neck motion [12]. Atlantoaxial subluxation presents similar symptoms with calcific tendinitis [13].
Mainly, diagnosis is based on the clinical findings combined with radiographic demonstration of characteristic calcifications. Most cases show calcificated lesion in plain radiograph and CT. The CT scan can help identify calcific deposits, which can often appear faint on plain radiograph, if it is invisible apparent calcification lesion on plain radiograph. The CT findings of retropharyngeal calcific tendinitis include prevertebral soft tissue thickness, and amorphous calcification, particularly at the anterior to C1-C2 level $[4,14]$. The calcification showed low or high signal on T1 and high signal on T2-weighted MRI.

However, MRI is insensitive for the demonstration of calcification of the tendon compared to CT.

MRI is not typically necessary for this diagnosis but can sometimes demonstrate soft tissue swelling, abnormality of disc or vertebra, spread around in the adjacent vertebrae [14].

Retropharyngeal calcific tendinitis is a self-limiting condition and spontaneously resolves after 1-2 weeks. NSAIDs are usually sufficient; however, some patients may require a short course of corticosteroids if the symptoms are severe. Most patients can be recovered with conservative treatment such as NSAIDs in general but difficult to considered accurate diagnosis in the absence of radiological findings.

Acute longus colli tendinitis is a rare condition. So, we need to distinguish more serious causes of acute neck pain such as retropharyngeal abscess. Retropharyngeal abscess, the most feared alternative diagnosis, can be life-threatening. It more frequently affects young children causing fever, neck pain, dysphagia. Leukocytosis is common. Plain radiographs often show prevertebral widening with or without gas in the soft tissues, while CT imaging shows a hypodense region in the retropharyngeal space with ring enhancement [15]. Atlantoaxial subluxation is also differential diagnosis to acute longus colli tendinitis and can be confirmed by CT.

Acute longus colli tendinitis is an important consideration in the differential diagnosis of acute neck pain. If a patient 
is suspected with acute longus colli tendinitis, CT should be preferentially considered over MRI for accurate diagnosis. With the radiographic finding, by observing that relieving symptoms with conservative therapy such as administration of NSAIDs it will be able to confirm the diagnosis and the treatment at the same time.

When patients present with acute symptoms such as neck pain and dysphagia without specific findings of plain radiograph, calcific prevertebral tendinitis should be included in the differential diagnosis. If highly suspicious, further study with CT scan can be helpful.

\section{References}

1. GBD 2016 DALYs and HALE Collaborators (2017) Global, regional, and national disability-adjusted life-years (DALYs) for 333 diseases and injuries and healthy life expectancy (HALE) for 195 countries and territories, 1990-2016; a systematic analysis for the Global Burden of Disease study 2016; Lancet 390(10100): 1260-1344.

2. Fejer R, Kyvik KO, Hartvigsen J (2006) The prevalence of neck pain in the world population: a systematic critical review of the literature. Eur Spine J 15(6): 834-848.

3. Moskovich R (1998) Neck pain in the elderly: common causes and management. Geriatrics 43(4): 65-70.

4. Bladt O, Vanhoenacker R, Bevernage C, Van Orshoven M, Van Hoe L, et al. (2008) Acute calcific prevertebral tendinitis. JBR-BTR 91(4): 158159.

5. Chung T, Rebello R, Gooden EA (2005) Retropharyngeal calcific tendinitis: case report and review of literature. Emergency Radiology
11(6): 375-380.

6. Rojas CA, Vermess D, Bertozzi JC, Whitlow J, Guidi C, et al. (2009) Normal thickness and appearance of the prevertebral soft tissues on multidetector CT. AJNR Am J Neuroradiol 30(1): 136-141.

7. Hartley J (1964) Acute cervical pain associated with retropharyngeal calcium deposit: A case report. J Bone Joint Surg Am 46(8): 1753-1754.

8. Ring D, Vaccaro AR, Scuderi G, Pathria MN, Garfin SR (1994) Acute calcific retropharyngeal tendinitis. Clinical presentation and pathological characterization. J Bone Joint Surg Am 76(11): 1636-1642.

9. De Maeseneer M, Vreugde S, Laureys S, Sartoris DJ, De Ridder F, et al. (1997) Calcific tendinitis of the longus colli muscle: case report. Head and Neck 19(6): 545-548.

10. Omezzine SJ, Hafsa C, Lahmar I, Driss N, Hamza H (2008) Calcific tendinitis of the longus colli: diagnosis by CT. Joint Bone Spine 75(1): 90-91.

11. Razon RV, Nasir A, Wu GS, Soliman M, Trilling J (2009) Retropharyngeal calcific tendonitis: report of two cases. J Am Board Fam Med 22(1): 8488.

12. Reilly BK, Reilly JS (2012) Retropharyngeal abscess: diagnosis and treatment update. Infect Disord Drug Targets 12(4): 291-296.

13. Yang SY, Boniello AJ, Poorman CE, Chang AL, Wang S, et al. (2014) A review of the diagnosis and treatment of atlantoaxial dislocations. Global Spine J 4(3): 197-210.

14. Eastwood JD, Hudgins PA, Malone D (1998) Retropharyngeal effusion in acute calcific prevertebral tendinitis: diagnosis with CT and MR imaging. AJNR Am J Neuroradiol 19(9): 1789-1792.

15. Roldan CJ, Carlson PJ (2013) Longus colli tendonitis, clinical consequences of a misdiagnosis. Am J Emerg Med 31(10): 1538.e11538.e2.

\section{Your next submission with Juniper Publishers will reach you the below assets}

- Quality Editorial service

- Swift Peer Review

- Reprints availability

- E-prints Service

- Manuscript Podcast for convenient understanding

- Global attainment for your research

- Manuscript accessibility in different formats

( Pdf, E-pub, Full Text, Audio)

- Unceasing customer service

Track the below URL for one-step submission https://juniperpublishers.com/online-submission.php 